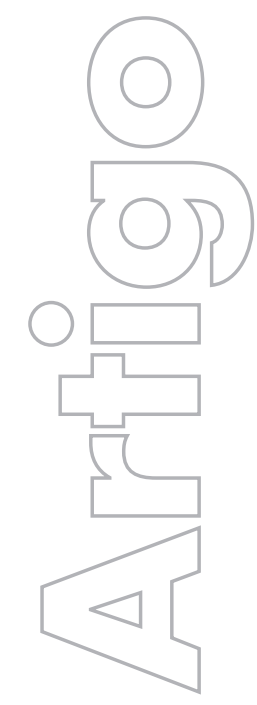

revista

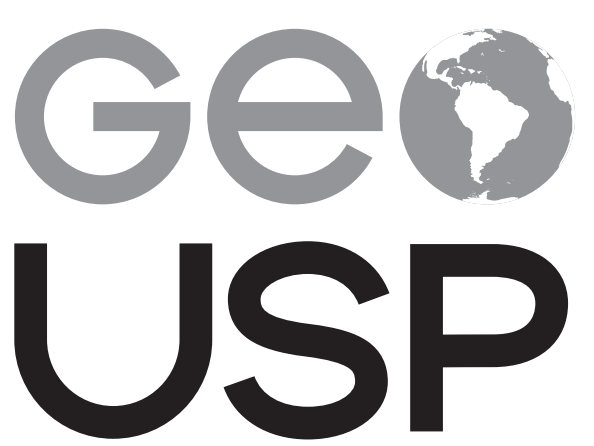

espaço e tempo

Volume $19 \cdot n^{\circ} 3(2015)$

\section{Dinâmica econômica} e cidades médias: uma análise sobre a cidade de Uberaba na região do Triângulo Mineiro

\author{
Maria Terezinha Serafim Gomes \\ Unesp
}

p. $516-534$

Como citar este artigo:

GOMES, M. T. S. Dinâmica econômica e cidades médias: uma análise sobre a cidade de Uberaba na região do Triângulo Mineiro. Geousp - Espaço e Tempo (Online), v. 19, n. 3, p. 516-534, mês. 2016. ISSN 2179-0892.

Disponível em: URL: http://www.revistas.usp.br/geousp/ article/view/81733. DOI: http://dx.doi.org/10.11606/ issn.2179-0892.geousp.2015.81733.

\section{(c) $($ i) $(5)$}

Este artigo está licenciado sob a Creative Commons Attribution 4.0 License. 


\title{
Dinâmica econômica e cidades médias: uma análise sobre a cidade de Uberaba na região do Triângulo Mineirol
}

\section{Resumo}

Atualmente, as cidades médias vêm assumindo um papel significativo na rede urbana brasileira. Elas crescem mais que as metrópoles, passando a ser destino não apenas de populações, mas também de novos investimentos empresariais nos setores da indústria, do comércio e dos serviços. Com o processo de desconcentração econômica e industrial a partir da metrópole de São Paulo, as empresas começaram a buscar lugares mais vantajosos e sem as "deseconomias de aglomeração" dos grandes centros urbanos e metrópoles. Nesse contexto, as cidades médias vêm-se configurando como "cidades emergentes", numa nova dinâmica econômica fora do espaço metropolitano. Estão localizadas sobretudo nas regiões Sul e Sudeste do país. Este artigo discute a dinâmica econômica e cidades médias, tomando como referência Uberaba, na região do Triângulo Mineiro.

Palavras-chave: Desconcentração econômica e industrial. Cidades médias. Dinâmica econômica.

\section{Economic dynamic and medium-sized cities: an analysis of the city of Uberaba, Triangle region of Minas Gerais}

\begin{abstract}
In the current period, medium-sized cities have assumed an important role in the Brazilian urban network. These cities grow more than the metropolis passing thus to destination not only of population but also new business investment in the sectors of industry, commerce and services. With the process of economic and industrial decentralization from the metropolis of Sao Paulo, companies began to seek places more advantageous and without the "agglomeration diseconomies" present in large urban centers and metropolitan locations. In this context, the medium-sized cities have configured as "emerging cities", a new economic dynamics out of the metropolitan area. They are located mainly in the South
\end{abstract}

1 Este trabalho faz parte das discussões do projeto de pesquisa Dinâmica Econômica, Cidades Médias e Interações Espaciais, financiado pela Fapemig (2011-2013). 
and Southeast regions of the country. This article aims to discuss the economic dynamics and medium-sized cities, with reference to city of Uberaba, in the Triangle region of Minas Gerais.

Keywords: Economic and industrial decentralization. Medium-sized cities. Economic dynamics.

\section{Introdução}

Nas últimas décadas, as cidades médias² têm se tornado destino não apenas de população, mas também de novos investimentos empresariais favorecidos pelo movimento de desconcentração econômica e industrial a partir de São Paulo. Desse modo, passam a desempenhar um novo papel na divisão territorial do trabalho e na rede urbana brasileira.

Esse movimento de desconcentração foi acompanhado pelo "[...] aumento da heterogeneidade interna das regiões brasileiras, com o surgimento de ilhas de produtividade em quase todas as regiões, o crescimento relativo maior das antigas periferias nacionais e a importância maior do conjunto das cidades médias perante as áreas metropolitanas", conforme destacou Pacheco (1999, p. 5). Com efeito, as cidades médias, consideradas lugares de "possibilidades", são "ganhadoras" no processo de desconcentração industrial (Gomes, 2007), já que continuam sendo atrativas tanto para população quanto para empresas dos setores da indústria, do comércio e dos serviços, assumindo, assim, a tendência de se transformar em "novos espaços produtivos", com investimentos nacionais e estrangeiros.

Nesse cenário, as cidades médias, localizadas principalmente nas regiões Sul e Sudeste do país, ${ }^{3}$ configuram-se como "cidades emergentes", alavancando uma nova dinâmica econômica fora do espaço metropolitano. No contexto da reestruturação produtiva e da desconcentração econômica e industrial, os espaços de produção extrapolam, porém, os limites do estado de São Paulo, fazendo surgir "novos espaços produtivos" nas regiões do sul de Minas Gerais, do norte do Rio de Janeiro, do norte do Paraná e do Triângulo Mineiro, entre outras.

$\bigcirc$ presente texto tem a pretensão de abordar a dinâmica econômica em cidades médias, tendo como referência a cidade de Uberaba, na região do Triângulo Mineiro. Para tanto, foram realizadas uma revisão bibliográfica acerca do tema, pesquisas em fontes secundárias, a partir da Rais (Relação Anual de Informações Sociais), do IBGE (Instituto Brasileiro de Geografia e Estatística) e da Fundação João Pinheiro (FJP), bem como visitas à Prefeitura Municipal de Uberaba e pesquisa de campo em sete empresas industriais.

2 No Brasil, o debate sobre cidades médias surgiu nos anos 1970 e ganhou dimensão nos anos 1990, com várias perspectivas de análise. O IBGE toma como referência o tamanho demográfico e considera "cidades médias" aquelas que têm entre 100 e 500 mil habitantes; outros pesquisadores consideram o papel desempenhado pela cidade. Entre eles, podemos destacar: Amorim Filho (1984), Amorim Filho e Serra (2001), Soares (1999, 2005), Sposito (2001, 2004, 2007, 2009, 2010) e Corrêa (2006, 2007).

Em 2007, foi criada a Rede de Pesquisadores sobre Cidades Médias (Recime), coordenada pela Profa Maria Encarnação Beltrão Sposito, da Unesp de Presidente Prudente, com a participação de pesquisadores de diversas regiões brasileiras. Além da Recime, há a Rede Brasileira de Estudos sobre Cidades Médias: uma Abordagem Multidisciplinar, com sede em Recife, na Universidade Federal de Pernambuco, e de que participam pesquisadores de várias áreas do conhecimento.

3 Sublinhe-se que, não obstante o destaque dado ao crescimento de cidades médias nas regiões Sul e Sudeste, o processo é observado também no Nordeste, por exemplo, nos municípios de Sobral, Crato e Juazeiro do Norte (CE), Petrolina (PE), Juazeiro, Feira de Santana e Barreiras (BA) e Mossoró (RN), entre outros. 
No percurso deste trabalho, faremos, inicialmente, uma breve exposição sobre o processo de desconcentração econômica e industrial a partir de São Paulo e a inserção da Região do Triângulo Mineiro. Em seguida, abordaremos a dinâmica econômica da cidade de Uberaba, destacando seu papel regional.

Uberaba, localizada na região do Triângulo Mineiro, tem uma população de aproximadamente 318.813 habitantes (IBGE, 2014). Está numa posição geográfica estratégica, distando cerca de 500 km de centros urbanos nacionais importantes, como São Paulo, Belo Horizonte, Goiânia e Brasilia, aos quais está interligada por meio de rodovias federais e estaduais, sendo sua ligação até a capital paulista feita por autopista duplicada, a BR-050, cujo trecho paulista é denominado SP330, Rodovia Anhanguera. Conta com um ramal ferroviário (Ferrovia Central Atlântica - FCA), sistema de comunicações através de fibra ótica e voos diários para São Paulo e Belo Horizonte.

\section{Desconcentração econômica e industrial e as transformações na região do Triângulo Mineiro}

Para compreendermos as transformações que vêm ocorrendo na região do Triângulo Mineiro, é preciso, antes, discorrer sobre o movimento de desconcentração econômica e industrial a partir de São Paulo, já que "[...] a estrutura socioeconômica dessa região foi diretamente afetada, iniciando uma nova fase de sua economia, representada pela expansão e pela modernização da agropecuária”, conforme destaca Guimarães (1990).

A indústria esteve concentrada na região metropolitana de São Paulo (RMSP) até os anos 1970, quando teve início o processo de desconcentração industrial em direção ao interior do estado de São Paulo e a outros estados. ${ }^{4}$ Esse movimento às demais regiões do país vem ocorrendo desde as décadas de 1980 e 1990, como corolário da Política de Descentralização Industrial, iniciada na década de 1970, no âmbito estadual, e do Plano Nacional de Desenvolvimento (PND), na esfera federal, que preconizava uma maior intervenção do Estado para propiciar o desenvolvimento e reduzir as desigualdades regionais.

Segundo Campolina Diniz (1995), esse processo foi desencadeado por fatores como: as "deseconomias de aglomeração" em São Paulo e a consequente criação de "economias de aglomeração" em outros locais; a política estatal que concedia benefícios sob a forma de incentivos, investimentos diretos e infraestrutura; o movimento das fronteiras agrícola e mineral; e a unificação do mercado por meio da infraestrutura de transportes e comunicações.

Não obstante a continuidade do movimento de desconcentração econômica e industrial em direção a áreas mais vantajosas para a reprodução do capital, observa-se, como destacou Diniz (1995), uma reconcentração de alguns setores produtivos na área mais desenvolvida do país, movimento que

[... está relacionado com as mudanças tecnológicas e com a reestruturação produtiva, as quais tendem a alterar os requisitos locais, especialmente daquelas atividades mais intensivas em conhecimento. Além disso, as mudanças ideológicas e políticas no que diz respeito ao papel do Estado, a abertura externa da economia,

4 Vários autores têm tratado da desconcentração industrial: Azzoni (1985), Lencioni (1991), Cano (1997), Diniz (1993, 1995), Negri (1992), Guimarães Neto (1997), Pacheco (1998), Tinoco (2001) e Tunes (2004), entre outros. 
em especial do Mercosul, e o processo de democratização seguramente terão efeitos decisivos sobre a configuração regional da indústria no Brasil, indicando a possibilidade de sua reaglomeração na região Centro-Sul do país. (Diniz, 1995, p. 10)

Na mesma perspectiva de análise, Guimarães Neto (1997, p. 65-66) destacou também alguns elementos que contribuíram para o processo de desconcentração industrial, entre eles: a consolidação de complexos agroindustriais voltados à exportação, como café, soja, laranja e carne bovina; a produção de álcool combustível a partir da cana-de-açúcar; a implantação de refinarias do setor petroquímico; a instalação de centros de pesquisa em cidades médias; as políticas de proteção ao meio ambiente e outras deseconomias externas que impõem aos novos projetos industriais uma localização fora da área metropolitana; e a organização dos sindicatos de trabalhadores da região metropolitana e perimetropolitana.

Nesse contexto, o movimento da indústria em direção ao interior ocorre, por um lado, em função das "deseconomias de aglomeração" presentes na área metropolitana, como o aumento de preços dos terrenos e dos imóveis, congestionamentos diários, dificultando, assim, a mobilidade. Por outro lado, muito contribuiu para ele a ação do Estado - com investimentos fiscais e desenvolvimento de infraestruturas de transportes e comunicações - acompanhada, também, pelo movimento da fronteira agrícola e mineral, entre outros fatores.

Como decorrência, observou-se uma queda, em termos relativos, da participação de São Paulo no total da produção industrial do país: se em 1970, sua taxa de participação era de 58,1\%, em 1990, caiu para 49,2\%. O mesmo ocorreu com a Região Metropolitana de São Paulo - RMSP, cuja taxa de participação passou de 43,40\%, em 1970, para 26,2\%, em 1990. O interior do estado, porém, que apresentava índice de 14,7\% em 1970, subiu para 23,0\% em 1990, com destaque para as regiões próximas à capital paulista, como Campinas, Vale do Paraiba e Sorocaba. Nesse mesmo período (1970-1990), outros estados aumentaram sua participação na produção industrial, como Bahia (de 1,5\% para 4,0\%), Minas Gerais (de 6,4\% para 8,7\%), Paraná (de 3,1\% para 5,7\%), Santa Catarina (de 2,6\% para 4,2\%) e Rio Grande do Sul (de 6,3\% para 7,7\%) (Tabela 1).

\section{Tabela 1 - Brasil, regiões e estados selecionados: distribuição espacial da indústria de transformação (1970-1990)}

\begin{tabular}{|c|c|c|c|c|c|}
\hline região/estado & 1970 & 1975 & 1980 & 1985 & 1990 \\
\hline Nordeste (menos BA) & 4,2 & 4,5 & 4,4 & 4,8 & 4,5 \\
\hline Bahia & 1,5 & 2,1 & 3,1 & 3,8 & 4,0 \\
\hline Minas Gerais & 6,4 & 6,3 & 7,8 & 8,3 & 8,7 \\
\hline Rio de Janeiro & 15,7 & 13,6 & 10,2 & 9,5 & 9,8 \\
\hline São Paulo & 58,1 & 55,9 & 54,4 & 51,9 & 49,2 \\
\hline a) metrópole & 43,4 & 38,8 & 34,2 & 29,4 & 26,2 \\
\hline b) interior & 14,7 & 17,1 & 20,2 & 22,5 & 23,0 \\
\hline Paraná & 3,1 & 4,0 & 4,1 & 4,9 & 5,7 \\
\hline Santa Catarina & 2,6 & 3,3 & 3,9 & 3,9 & 4,2 \\
\hline Rio Grande do Sul & 6,3 & 7,5 & 7,9 & 7,9 & 7,7 \\
\hline outros estados & 2,1 & 2,8 & 4,2 & 5,0 & 6,2 \\
\hline total & 100,0 & 100,0 & 100,0 & 100,0 & 100,0 \\
\hline
\end{tabular}

fonte: Negri (1996, p. 143). 
Nos anos 2000, a participação da indústria paulista de transformação continua diminuindo e atinge 47,8\% em relação ao Brasil, assim como a da RMSP, que chega a 20,7\%, enquanto segue aumentando a participação do interior, atingindo $27,1 \%$, segundo dados do IBGE (apud Gomes, 2007).

O processo de desconcentração econômica e industrial a partir de São Paulo contribuiu para a formação de uma "região metropolitana desconcentrada", de acordo com Lencioni (1998, p. 31), fundamentada "na crescente centralização do capital" com a "atuação das empresas oligopolísticas e dos grupos econômicos que foram os principais promotores do deslocamento das atividades industriais para o interior". Assim, paralelamente ao movimento de desconcentração econômica e industrial em direção ao interior de São Paulo e a outros estados, ocorre, na metrópole paulista, a concentração da gestão e de serviços especializados, e também de infraestruturas essenciais para a gestão e administração empresarial, como as sedes de empresas que mantêm unidades fabris no interior de São Paulo e também em outros estados. ${ }^{5}$

A dispersão das atividades econômicas pelo território deve-se às "condições gerais de produção" presentes nas novas localidades, entre elas, infraestruturas, como aeroportos, ferrovias, rodovias, fibras óticas, equipamentos e serviços especializados para apoio ao desenvolvimento das atividades produtivas. No entanto, tais condições não são homogêneas, pois estão presentes de forma seletiva no território, acarretando assimetrias regionais. As regiões próximas ao estado de São Paulo têm sido favorecidas, graças à "densidade técnica, científica e informacional" e à "fluidez do território", conforme Milton Santos (1994,1999).

No processo de desconcentração econômica e industrial, as "cidades médias" parecem tornar-se núcleos importantes de localização de novos investimentos empresariais ligados aos setores da indústria, do comércio e de serviços, dadas as "condições gerais de produção" nelas existentes, que favorecem a instalação de novos capitais produtivos. Isso revela a presença de economias de aglomeração e vantagens locacionais adequadas à reprodução do capital nessas cidades, expressas em infraestrutura de transporte, energia e telecomunicações e serviços modernos (Negri; Pacheco, 1994; Diniz; Crocco, 1996), o que faz com que elas assumam importância na divisão territorial do trabalho, constituindo uma nova dinâmica econômica fora do espaço das metrópoles.

Com efeito, as condições gerais de produção presentes nas cidades médias contribuem para o surgimento de novos espaços produtivos que extrapolam o limite do estado de São Paulo. É nesse contexto que se insere a região do Triângulo Mineiro, considerada também um "novo espaço produtivo", com a instalação de grandes grupos econômicos dos setores do comércio e da indústria, em especial os ligados à agroindústria.

A partir da década de 1960, e principalmente durante os anos 1970, a região do Triângulo Mineiro e Alto Paranaiba ${ }^{6}$ vivenciou um processo de modernização do setor agropecuário, com incorporação das áreas do cerrado ao processo produtivo. Nessa época, foram criados alguns programas para o desenvolvimento dessas áreas, entre eles: Programa de Crédito Integrado e Incorporação dos Cerrados (PCI), Programa de Assentamento Dirigido do Alto Paranaiba (Padap), Programa de Desenvolvimento dos Cerrados (Polocentro) e Programa de Cooperação Nipo-Brasileira para o Desenvolvimento dos Cerrados (Prodecer).

5 Para mais detalhes, consultar Lencioni (1991, 1998, 2003, 2011).

6 Para mais detalhes, consultar Cleps Junior (1998). 
O processo de modernização da agricultura na região, com a aplicação de novas técnicas de produção, favoreceu o aumento da produtividade e o uso intensivo da terra. As terras antes ocupadas pelo cerrado e por pastagens passaram a ser agricultáveis, e a região do Triângulo Mineiro/Alto Paranaiba tornou-se grande produtora de café e de grãos (soja, milho e feijão, principalmente). Nas últimas décadas, todavia, tem-se disseminado a plantação de cana-de-açúcar nas áreas de cerrado, onde se observa a presença de grupos nordestinos que fizeram grandes investimentos no setor sucroalcooleiro local, como Tércio Wanderley, da usina Coruripe, que em 1997 investiu na construção de uma unidade no município de Iturama e, em 2002, no município de Campo Florido, e o grupo Carlos Lyra, que em 2003 instalou unidades produtivas nos municípios de Volta Grande e Delta. ${ }^{?}$

Como se percebe, a região do Triângulo Mineiro foi marcada, ao longo do século XX, por um processo de diversificação produtiva, com desenvolvimento de atividades agropecuárias e da agroindústria moderna, bem como de atividades comerciais, industriais e de serviços, alterando a dinâmica das cidades médias da região, como Uberlândia e Uberaba.

Tais transformações implicaram mudanças nas principais cidades da rede urbana regional do Triângulo Mineiro e Alto Paranaiba. Uberlândia, por exemplo, é considerada uma "grande cidade média", pois "trata-se de uma cidade regional, haja vista sua capacidade de organização e direção da vida regional". Já Uberaba, Pato de Minas, Araguari e Ituiutaba incluem-se propriamente na categoria de cidades médias, enquanto Araxá, Patrocínio, Frutal e Monte Carmelo podem ser consideradas grandes cidades locais, tendo em vista o papel que desempenham em suas respectivas microrregiões (Bessa, 2007, p. 12).

A cidade de Uberlândia, no decorrer do século XX, transformou-se no principal centro urbano da região do Triângulo Mineiro e Alto Paranaiba, ocupando, com suas relações em nível nacional, um papel de destaque na rede urbana do país. Articulada à metrópole nacional, São Paulo, mantém igualmente relações com outros centros urbanos importantes como Belo Horizonte, Brasilia, Goiânia, entre outros, conforme destacou Bessa (2007).

Quanto a Uberaba, convém destacar que no século XIX, sobretudo na primeira metade, a cidade constituía o principal centro urbano da região, chamada Sertão da Farinha Podre. Dada sua localização privilegiada, tornou-se um nó de articulação das vias de transporte terrestre e um dos pontos principais de parada dos viajantes da época, assumindo a posição de "cidade primaz", um entreposto comercial que tanto abastecia São Paulo com produtos primários goianos e mato-grossenses, quanto comercializava com Goiás e Mato Grosso os produtos industrializados provenientes de São Paulo. Além disso, concentrava as atividades comerciais, bem como uma diversidade de profissionais, juristas, médicos, farmacêuticos e cirurgiões, professores, comerciantes e guarda-livros, funcionários públicos etc., favorecendo o crescimento urbano e o desenvolvimento econômico nesse período, conforme destacou Lourenço (2007).

Segundo Lourenço (2010, p. 87)

[...] Uberaba era o nó de um sistema radial de estradas, os entrepostos obrigatórios de todos os fluxos mercantis de norte e oeste, dos territórios de Goiás e Mato Grosso. Nessa situação, os negociantes ali radicados estavam em posição favorável para extrair grande parte do excedente gerado pela economia situada

7 Paiva e Ribeiro (1997 apud Bittencourt; Lima, 2012) e Castro e Moura Filho (2009 apud Bittencourt; Lima, 2012). 
a montante, por meio de manipulação das condições de mercado. Uberaba também centraliza atividades como atendimento médico, educação, acesso à justiça e administração pública.

No final do século XIX e início do século XX, criou-se na região do Triângulo Mineiro, uma base de infraestrutura associada aos transportes, com a extensão dos trilhos da Companhia Mogiana de Estradas de Ferro (1888), a construção da ponte Afonso Pena (1910), sobre o rio Paranaiba (ligação com o sul e o sudoeste goiano), e de uma malha de estradas de rodagem (1912), que acelerou a circulação de mercadorias e de informações e, ao mesmo tempo, estreitou e ampliou os vínculos com São Paulo, conforme destacou Bessa (2007). Até a chegada dos trilhos da Cia. Mogiana de Estradas de Ferro - Ferrovia Centro Atlântica (FCA), em 1888, Uberaba se destacava como principal cidade da região, contudo, com a extensão da ferrovia até Uberlândia (1895) e, posteriormente, até Araguari (1896), favorecendo essas cidades na rede urbana da região, Uberaba começou a perder seu papel de polarização regional.

Tais mudanças acarretaram alterações nas funções dessas cidades e na estruturação da rede urbana regional, como afirma Bessa (2007): com "a implantação das rodovias e da constituição de um entroncamento rodoferroviário", Uberlândia passou a acolher funções, especialmente funções regionais. Ainda de acordo com Bessa (2007, p. 15), devido à capacidade de absorver os impulsos da economia nacional, mantendo-se fortemente articulada com a economia paulista, e à implantação de novas formas de organização das atividades produtivas, possibilitadas principalmente pela ausência de formas pretéritas e fortemente impulsionadas por um processo de alavancagem orientado pelas atitudes e investimentos de sua elite, Uberlândia assumiu posição de comando, com prejuízo de Uberaba, que foi esvaziada de uma parcela de suas funções, principalmente as regionais, ocorrendo, a partir de então, uma dinâmica divergente na estruturação do espaço regional, definida pela diferenciação entre esses lugares.

○ crescimento de Uberlândia, como já citado, foi favorecido pela implantação da ferrovia e de rodovias, que permitiu sua ligação com as demais regiões do próprio Triângulo Mineiro, bem como com os estados de Goiás e Mato Grosso, com destaque para as potencialidades de entreposto comercial. Em meados do século XX, despontava com o comércio atacadista e a industrialização alimentar de beneficiamento. Segundo Bessa (2007), a cidade já polarizava o comércio regional e inter-regional e foi bastante beneficiada com a expansão rodoviária do Plano de Metas, que resultou na ampliação dos seus mercados e na perda de importância de Uberaba e Araguari. De acordo com Bessa (2007, p. 161),

Triângulo Mineiro incorporou-se à economia nacional como periferia dinâmica de São Paulo e, por esta razão, consolidou seu papel histórico de intermediação entre territórios, tendo em vista que se aprofundou e complexificou a inserção anteriormente assegurada, com o aumento das interações espaciais. Tal intermediação, no entanto, orientou-se, do ponto de vista externo, pela complementaridade e, do ponto de vista interno, pela competição entre os principais centros da região, em particular, entre Uberaba e Uberlândia.

A partir dos anos 1970, técnicas modernas de agricultura promoveram uma reorganização da agropecuária no cerrado mineiro, com a incorporação da soja e da cana-de-açúcar. Uberaba desenvolveu o aprimoramento genético do gado zebuíno e a expansão da pecuária, enquanto em 
Uberlândia, a incorporação tecnológica ocorreu na avicultura e na suinocultura. Paralelamente, começaram a surgir agroindústrias na região com a instalação de processadoras de produtos agropecuários, em Uberlândia, e de fertilizantes fosfatados, em Uberaba, bem como se ampliou o comercio de uma série de serviços especializados e de apoio à atividade agrícola. Dessa forma, se Uberlândia se destacava como o principal centro industrial do Triângulo Mineiro desde os anos 1940, passou a dividir essa posição com Uberaba, principalmente nos anos 1980, quando esta recebeu investimentos na indústria química, em particular do setor de fertilizantes e defensivos agrícolas, localizada no Distrito III, às margens do Rio Grande, na divisa com São Paulo.

Além do crescimento no setor industrial, Uberaba assumiu importância, também a partir dos anos 1980, como centro de serviços na área da saúde, com a inauguração do Hospital de Clínicas da Universidade Federal do Triângulo Mineiro, em 1982, e com a instalação de outros estabelecimentos médico-hospitalares (clínicas especializadas e laboratórios) que possuem equipamentos de alta tecnologia, antes disponíveis apenas nos grandes centros urbanos.

Diante do exposto, cabe indagar que papel desempenha Uberaba, hoje, no contexto da região do Triângulo Mineiro. Suas funções e papéis urbanos mudaram ao longo do tempo, como bem explana Bessa (2007, p. 323):

[...] determinadas racionalidades sociais, econômicas e políticas foram predominantes e indicaram a existência de fatores de estancamento e regressão para Uberaba e de ascensão para Uberlândia e, por conseguinte, os movimentos de mudança da rede urbana regional. [...] a transição de um para outro significou a imposição de novas racionalidades e a redefinição dos atores, que, por sua vez, promoveram a recombinação dos elementos característicos às redes urbanas, reatualizando o seu padrão espacial. Num primeiro momento, observou-se o predomínio de uma racionalidade local, definida pela atividade pastoril, período em que se destacou a elite uberabense e uma espacialidade gestada a partir desse centro; em seguida, observou-se o momento dos embates entre racionalidades regionais, uma ainda associada à atividade pastoril e outra relacionada com as atividades mercantis, marcados pelos conflitos entre espacialidade marcada pela relativa paridade e simetria funcional, bem como pelo revezamento dos comandos; e finalmente, o momento de diversificação das racionalidades, no qual passaram a atuar atores de escalas distintas, locais, nacionais e internacionais, expresso por uma espacialidade com múltiplos circuitos, orientada por complementaridades e competitividades, bem como por coerências e rupturas, cujos benefícios foram mais bem aproveitadas por Uberlândia, que alargou sua importância tanto na escala regional, quanto em escala nacional, uma vez que sua elite mostrou-se muito mais apta a acolher os imperativos das subsequentes divisões territoriais do trabalho. (Bessa, 2007, p. 323)

Apesar de Uberlândia assumir o papel de principal centro polarizador da região do Triângulo Mineiro/Alto Paranaiba, Uberaba, além de vivenciar um crescimento no setor industrial, vem desempenhando um papel importante na rede urbana regional como centro de comércios, de serviços educacionais e médico-hospitalares, promovendo uma nova dinâmica econômica, conforme apresentaremos a seguir. 


\section{Uberaba e a nova dinâmica econômica}

A partir da década de 1970, com o avanço do processo de modernização do campo, algumas indústrias de insumos agrícolas começaram a se instalar na cidade de Uberaba, atraídas pelo desenvolvimento da agropecuária. Tais transformações favoreceram a migração campo-cidade, ocorrendo um aumento da população urbana na região do Triângulo Mineiro/Alto Paranaiba, principalmente nas cidades de Uberlândia e Uberaba (Tabela 2).

\section{Tabela 2 - Uberaba: evolução populacional (1970-2014)}

\begin{tabular}{c|c|c|c}
\hline anos & $\begin{array}{c}\text { população } \\
\text { urbana }\end{array}$ & $\begin{array}{c}\text { população } \\
\text { rural }\end{array}$ & $\begin{array}{c}\text { população } \\
\text { total }\end{array}$ \\
\hline 1970 & 108.259 & 16.231 & 124.490 \\
1980 & 182.519 & 16.684 & 199.203 \\
1991 & 200.705 & 11.119 & 211.824 \\
2000 & 244.171 & 7.880 & 252.051 \\
2010 & 289.376 & 6.612 & 295.988 \\
\hline 2014 & - & - & $318.813^{*}$ \\
\hline
\end{tabular}

fonte: IBGE $\left(2010,{ }^{8} 2014^{9}\right.$ apud Carvalho, 2004, p. 26).

* estimativa

A partir dos anos 1970, Uberaba vivencia transformações socioespaciais e um crescimento populacional bastante expressivo, chegando quase a dobrar seu número de habitantes entre 1970 e 1980, do que resulta um aumento da demanda por bens e serviços. Entre os anos de 1991 e 2010, observa-se igualmente um crescimento significativo da população urbana, que passa de 200.705 para 289.376 habitantes, fenômeno já observado no país, principalmente nas décadas de 1970 e 1980, período de intenso êxodo rural. A população advinda do campo, contudo, encontrou poucas opções de trabalho e moradia na cidade e começou a ocupar algumas áreas pertencentes, então, à Rede Ferroviária Nacional, conforme destacou Reis (2012).

No âmbito da economia, Uberaba iniciou um processo de profundas transformações, a partir dos anos 1990, as quais podem ser observadas nos dados a seguir, relativos ao número de estabelecimentos e trabalhadores e ao Produto Interno Bruto (PIB).

Na Tabela 3, os dados da Rais (MTE, [s.d.]) revelam o crescimento da participação dos setores de atividades econômicas (comércio, serviços, indústria) no período analisado. Comércio e serviços tiveram o melhor desempenho, expresso no número de estabelecimentos comerciais, que subiu de 1.024 em 1985 para 1.278 em 1990, chegando a 1.925 em 1995. Em 2000, registra-se um crescimento significativo, com 2.408 estabelecimentos e, em 2013, eles chegam a 3.472; o setor de serviços foi o que mais cresceu nas duas últimas

8 IBGE. Instituto Brasileiro de Geografia e Estatística. Censo Demográfico 2010. Disponível em: <http://www.ibge. gov.br/home/mapa_site/mapa_site.php\#populacao>. Acesso em: 8 abr. 2014.

9 IBGE. Instituto Brasileiro de Geografia e Estatística. Estimativa de população 2014. Disponível em: <http:// www.cidades.ibge.gov.br/>. Acesso em: 8 abr. 2014. 
décadas, quase quadruplicando sua participação (de 907 estabelecimentos em 1985 para 3.336 em 2013). A indústria também teve um crescimento expressivo, com a entrada de capital externo à cidade, passando de 384 estabelecimentos em 1985 para 660 em 2000 e 891 em 2013. O setor agropecuário, por sua vez, passou de 81 estabelecimentos em 1985 para 1.170 em 2013. $\bigcirc$ aumento do número de estabelecimentos em todos os setores representou aumento também no número postos de trabalho e de trabalhadores ocupados em diferentes ramos de atividade.

Em dados percentuais, o crescimento econômico de Uberaba, no período de 1985 e 2013, registrou os seguintes índices: 139,03\%, para o setor industrial, 239,06\%, relativo ao comércio e, para o setor de serviços, 271,11\%; já o ramo do agronegócio atingiu a taxa de $1.344,4 \%$, e a construção civil, com 1.822,7\%, apresentou o maior crescimento no período analisado. Considerando, o conjunto de atividades econômicas, o crescimento foi de 295,17\%.

\section{Tabela 3 - Uberaba: número de estabelecimentos por setor de atividades econômicas (grande setor IBGE) (1985-2013)}

\begin{tabular}{l|r|r|r|r|r|r}
\hline IBGE grande setor & 1985 & 1990 & 1995 & 2000 & 2005 & 2013 \\
\hline indústria & 384 & 567 & 624 & 660 & 747 & 891 \\
construção civil & 44 & 277 & 487 & 599 & 542 & 846 \\
comércio & 1.024 & 1.278 & 1.925 & 2.408 & 2.865 & 3.472 \\
serviços & 907 & 946 & 1.465 & 2.051 & 2.341 & 3.366 \\
agropecuária & 81 & 127 & 1.220 & 1.270 & 1.335 & 1.170 \\
não classificados & 26 & 437 & 101 & - & - & - \\
\hline total & 2.466 & 3.632 & 5.822 & 6.997 & 7.830 & 9.745 \\
\hline
\end{tabular}

fonte: MTE ([s.d.]). organização: Maria Terezinha Serafim Gomes.

Com relação à participação de trabalhadores por setor de atividades econômicas, observa-se um crescimento significativo nos últimos 25 anos. No setor industrial, o número de trabalhadores passou de 8.096, em 1985, para 16.380, em 2013. No ano 2000, apresentou uma queda de $8,61 \%$, em relação a 1995 , e retomou o crescimento, em 2005, atingindo 12.806 trabalhadores, com 16,17\%. Outro setor que apresentou queda na participação dos trabalhadores foi o da construção civil, passando de 3.410 empregados, em 1995, para 3.084 e 2.017, em 2000 e 2005, respectivamente. Em 2013, houve recuperação dos empregos na construção civil, chegando a 8.504 trabalhadores. Entre os anos 1985 e 2013, o crescimento foi de 388,73\%.

No mesmo período, o comércio apresentou um bom desempenho, passando de 5.536 trabalhadores para 20.470. No setor de serviços, o crescimento também foi significativo, saltando de 13.389 para 42.407 trabalhadores. A participação de trabalhadores na agropecuária obteve igualmente crescimento, passando de 915, em 1985, para 4.109 trabalhadores, em 2013, aumento devido, principalmente, ao ramo sucroalcooleiro (Tabela 4). 


\section{Tabela 4 - Uberaba: número de trabalhadores por setor de atividades econômicas (grande setor IBGE) (1985-2013)}

\begin{tabular}{|c|c|c|c|c|c|c|}
\hline IBGE grande setor & 1985 & 1990 & 1995 & 2000 & 2005 & 2013 \\
\hline indústria & 8.096 & 8.278 & 12.062 & 11.023 & 12.806 & 16.380 \\
\hline construção civil & 1.740 & 2.439 & 3.410 & 3.084 & 2.017 & 8.504 \\
\hline comércio & 5.536 & 6.726 & 8.227 & 10.426 & 14.044 & 20.470 \\
\hline serviços & 13.389 & 14.155 & 17.892 & 22.210 & 30.198 & 42.407 \\
\hline agropecuária & 915 & 1.033 & 3.710 & 3.731 & 4.480 & 4.109 \\
\hline não classificados & 200 & 2.486 & 278 & - & - & - \\
\hline total & 29.876 & 35.117 & 45.579 & 50.474 & 63.545 & 91.874 \\
\hline
\end{tabular}

fonte: MTE ([s.d.]). organização: Maria Terezinha Serafim Gomes.

No que diz respeito à participação de trabalhadores por setores de atividades econômicas, houve um expressivo aumento do número de empregados nas áreas de comércio e de serviços, principalmente no período entre os anos 2000 e 2013. Esse dado está ligado à abertura de grandes hipermercados, à ampliação da oferta de prestação de serviços na cidade, principalmente educacionais - com a implantação de instituições públicas de ensino superior (UFTMe IFTM), ${ }^{10}$ além de outras, particulares, (Uniube, Facthus, Fazu, FCETM) ${ }^{11}$ - e de saúde - com o funcionamento de clínicas e laboratórios, assim como de hospitais, entre eles, Hospital de Clínicas da Universidade Federal do Triângulo Mineiro, Hospital Regional, Hospital Universitário Mário Palmério, Hospital São José, Hospital Beneficência Portuguesa, Hospital Hélio Angoti, Hospital São Domingos, Hospital São Marcos, Hospital Santa Lúcia.

Quanto à construção civil, houve um aumento considerável no número de empregos entre os anos de 2005 e 2013 (421,61\%), resultante da implantação de loteamentos fechados de alto padrão e outros empreendimentos residenciais e de comércios e serviços, além dos incentivos promovidos pelo governo federal, através de programas como o Minha Casa, Minha Vida, criado em 2009.

o setor agropecuário apresentou crescimento no número de trabalhadores, no período analisado, decorrente do desenvolvimento do ramo sucroalcooleiro no município, passando de 915 trabalhadores, em 1985, para 4.109, em 2013, com pequena oscilação de queda em relação ao ano de 2005, quando o setor empregava 4.480 trabalhadores.

Analisando os dados da participação dos setores da economia no Produto Interno Bruto (PIB) municipal de 2007, observa-se a predominância do setor de serviços, que correspondia a pouco mais de 50\% da composição total desse índice. O setor industrial vinha em segundo lugar, representando quase 30\% do PIB. Nesse mesmo ano, o que chamou a atenção foi o valor do setor agropecuário - 8\% do PIB -, o que demonstra que a agricultura e a pecuária têm um peso menor na economia em relação aos demais setores, não obstante o discurso propagado pelas elites de origem agrária da cidade sobre a importância econômica dessas atividades. Comparando com o de Minas Gerais, o PIB uberabense, no que concerne à participação dos setores, segue percentuais muito próximos à estrutura do PIB do estado, não havendo, portanto, grandes discrepâncias entre a estrutura econômica municipal e estadual.

10 Universidade Federal do Triângulo Mineiro, Instituto Federal de Educação, Ciência e Tecnologia do Triângulo Mineiro.

11 Universidade de Uberaba, Faculdade Novos Talentos, Faculdade de Zootecnia de Uberaba, Faculdade de Ciências Econômicas do Triângulo Mineiro. 
Tabela 5 - Uberaba: evolução e participação dos setores por atividade econômica no PIB - 2007 (em R\$1.000,00)

\begin{tabular}{l|r|r|r|r}
\hline setor de atividade econômica & Uberaba & \multicolumn{1}{c}{$\%$} & Minas Gerais & \multicolumn{1}{c}{$\%$} \\
\hline agropecuário & 435.691 & 8,03 & 16.854 .735 & 6,99 \\
industrial & 1.558 .047 & 28,71 & 66.341 .687 & 27,49 \\
serviço & 2.756 .016 & 50,78 & 127.032 .176 & 52,65 \\
outros (impostos) & 677.924 & 12,49 & 31.064 .455 & 12,87 \\
\hline total & 5.427 .678 & 100,00 & 241.293 .054 & 100,00 \\
\hline
\end{tabular}

fonte: Uberaba (2010).

Como se observa na Tabela 6, entre os anos de 1999 e 2010, o PIB de Uberaba mais que triplicou, acompanhando o desempenho do PIB mineiro, que também apresentou forte crescimento nessa década, em virtude da conjuntura econômica positiva, estimulada pelo crescimento por que passava o país. Nesse período, a cidade recebeu vários investimentos, tanto em atividades voltadas ao comércio e à prestação de serviços (hipermercados, hotéis, concessionárias, lojas de departamentos etc.), quanto no setor industrial, para atender a demanda do setor agropecuário, com a produção de insumos e a instalação de fábricas de fertilizantes, área em que o município se destaca, como um dos principais polos produtores. A concentração de indústrias de fertilizantes em Uberaba deve-se à facilidade de acesso a uma das principais matérias-primas nelas utilizada, a rocha fosfática, existente no município de Araxá (MG).

O PIB de Uberaba passou de 2.024.849 bilhões, em 1999, para 7.155.214 bilhões, em 2010 (Tabela 6).

Tabela 6 - Estado de Minas Gerais e municípios selecionados: PIB a preços correntes - 1999-2010 (em R\$1.000,00)

\begin{tabular}{lrrr}
\hline estado/região e município selecionado & 1999 & 2005 & \multicolumn{1}{c}{2010} \\
\hline estado de Minas Gerais & 89.789 .782 & 192.639 .256 & 351.380 .905 \\
\hline municípios selecionados & & & \\
\hline Belo Horizonte & 14.779 .149 & 28.951 .081 & 51.661 .760 \\
\hline região do Triângulo Mineiro & & & \\
\hline Araguari & 628.267 & 1.540 .196 & 2.212 .536 \\
Frutal & 251.954 & 477.315 & 923.485 \\
Ituiutaba & 478.259 & 977.428 & 2.025 .167 \\
Uberaba & 2.024 .849 & 4.105 .596 & 7.155 .214 \\
Uberlândia & 4.460 .210 & 9.196 .838 & 18.286 .904 \\
\hline Alto Paranaíba & & & \\
\hline Araxá & 552.198 & 1.158 .810 & 2.947 .025 \\
Patos de Minas & 624.057 & 1.235 .112 & 1.999 .571 \\
\hline
\end{tabular}


crescimento do PIB foi observado não apenas em Uberaba, mas também em outros municípios da região do Triângulo Mineiro/Alto Paranaíba, como Araguari, Frutal, Ituiutaba, Pato de Minas e Araxá, contribuindo para o aumento do PIB mineiro, que foi de 291,33\%, no mesmo período. Cabe lembrar que esses dados se devem ao processo de desconcentração econômica e industrial que favoreceu os estados limítrofes ao estado de São Paulo, com a atração de novos investimentos empresariais.

Analisando o valor adicionado nos setores da agropecuária, da indústria e de serviços, incluindo administração, saúde, educação pública e seguridade social, no período de 1999 a 2010, observa-se um crescimento significativo em todos os setores em Uberaba. Na agropecuária, o valor adicionado passou de 132.739,525 milhões, em 1999, para 551.237,097 miIhões, em 2010. No setor industrial, o valor subiu de 639.394,315 milhões para 2.138.619,204. Em relação aos serviços, o valor adicionado saltou, de 973.226,679 milhões em 1999, para 3.502.270,15, em 2010. No setor de administração, os valores foram, de 163.840,019 em 1999, para 581.825,753 milhões, em 2010 (Tabela 7).

\section{Tabela 7 - Uberaba: valor adicionado bruto por setor de atividades econômicas - 1999-2012 (a preços correntes - R \$1.000,00)}

\begin{tabular}{l|r|r|r|r}
\hline setor de atividade econômica & \multicolumn{1}{c|}{1999} & \multicolumn{1}{c}{2005} & \multicolumn{1}{c}{2010} & \multicolumn{1}{c}{2012} \\
\hline agropecuária & 132.740 & 371.795 & 551.237 & 685.221 \\
indústria & 639.394 & 1.218 .820 & 2.138 .619 & 2.461 .437 \\
serviços & 973.227 & 2.006 .740 & 3.502 .270 & 4.563 .714 \\
administração, saúde e educação públicas e & 163.840 & 315.873 & 581.826 & 707.314 \\
seguridade social & & & \\
\hline
\end{tabular}

fontes: IBGE (2012) e Minas Gerais (2013b).

Os dados revelam uma tendência de dinamismo no município de Uberaba nos últimos anos, reforçando a tese de que as cidades médias vêm se tornando lugares estratégicos para a reprodução do capital. A cidade vem passando por transformações em sua dinâmica econômica, com a implantação de novas indústrias, como a Black E Decker, e outras, do ramo agropecuário, como Vale Fertilizantes, Bunge Brasil, ${ }^{12}$ Dagranja, Sipcam, Stoppani do Brasil, Agronelli Insumos Agrícolas, Fertigran, Yara Brasil Fertilizantes, Ouro Fino, Heringer Fertilizantes, FMC Química do Brasil e Fertipar.

Observam-se, também, outros investimentos, entre eles: a instalação da rede atacadista Makro, de lojas de franquias e de departamentos, bem como empreendimentos residenciais (Cyrela Landascape Uberaba, Residencial Estâncias dos Ypês, entre outros) e a construção, em andamento, do Praça Uberaba Shopping (Grupo 5R), com 147 lojas, supermercado, hotel, restaurante, universidade, academia e condomínio residencial, além do lançamento anunciado do Uberaba Power Center (Grupo Andrade Gutierrez e Grupo BNC Corporate), que será implantado às margens da rodovia BR-050 (que liga São Paulo a Brasília), com previsão de abrigar um hipermercado, lojas âncoras, 187 lojas, 22 fast foods, quatro restaurantes, seis cinemas,

12 Agora adquirida pela Yara Brasil Fertilizantes. 
área de jogos, com pista de boliche, e 5.234 vagas de estacionamento, além de hotel e centro de convenções (Uberaba, 2012). Ademais, conforme já dito, a posição estratégica, a disponibilidade de força de trabalho de Uberaba tem favorecido a entrada de novos investimentos ligados ao setor industrial, principalmente da agroindústria ou comércios e serviços.

As empresas pesquisadas revelaram que mantêm relação com o mercado regional e nacional e, também, internacional, seja para o destino da produção, seja para a aquisição de matérias-primas. $\bigcirc$ circuito produtivo envolvendo a distribuição dos produtos extrapola o âmbito local, promovendo assim uma dinâmica econômica urbana e regional, em Uberaba, e redefinindo a divisão territorial do trabalho. Graças às melhorias dos transportes e das telecomunicações, tornaram-se possíveis as relações não apenas com cidades próximas, mas também com as mais distantes.

As cidades médias, em termos percentuais de população, continuam apresentando um crescimento maior do que o das metrópoles. $\bigcirc$ mesmo ocorre na economia, haja vista que, "nos últimos anos, as cidades médias foram aquelas que apresentaram maior crescimento anual do PIB (cerca de 4,7\% ao ano) e crescimento mais elevado da população (aproximadamente 2\% ao ano)" (Motta; Mata, 2009).

Em Uberaba não foi diferente, pois, como já citado, a cidade vem passando por transformações na dinâmica econômica e urbana, com a atração de novos investimentos nos diferentes setores de atividades econômicas, resultando, consequentemente, no crescimento do PIB e da população. Apesar das mudanças em curso, ela ocupa a $210^{\circ}$ posição no ranking de cidades brasileiras no Índice de Desenvolvimento Humano (IDH), que atingiu 0,772, em 2010, segundo o IBGE (2010).

\section{Considerações finais}

As cidades médias vêm se configurando como "novo espaço produtivo" na rede urbana brasileira, fora do espaço metropolitano.

A discussão sobre Uberaba revela que o processo de desconcentração econômica e industrial a partir de São Paulo concorreu para alterar significativamente a dinâmica econômica da cidade e do município, participando da consolidação do setor agroindustrial, com a instalação de fábricas de insumos agrícolas e de outros ramos como a empresa Black $E$ Decker, antes instalada na Região Metropolitana de São Paulo e que, graças aos incentivos fiscais, transferiu-se para a cidade.

Esse movimento do capital produtivo para Uberaba só foi possível em face de suas condições gerais de produção, como serviços especializados e infraestrutura de transporte e comunicação, tornando-a competitiva na atração desses novos investimentos.

$\bigcirc$ município de Uberaba é uma das principais economias mineiras, ocupando a sexta posição na composição do PIB estadual (Minas Gerais, 2013a). Já seu PIB agropecuário estava em primeiro lugar em 2011.

Além disso, observa-se o crescimento do PIB municipal em todos os setores de atividades econômicas, assim como o aumento do número de estabelecimentos e trabalhadores, em particular na indústria. Esses indicadores revelam a tendência da nova dinâmica econômica de Uberaba: sinergia para atrair novos investimentos. 
A cidade oferece uma diversidade de comércio e de serviços, sobretudo nas áreas da saúde (clínicas especializadas, laboratórios) e da educação, atraindo um grande fluxo de pessoas em nível regional. A própria transformação da Faculdade de Medicina em Universidade Federal do Triângulo, em 2005, concorreu para o movimento pendular de pessoas de outros municípios da microrregião de Uberaba, bem como das cidades paulistas próximas à divisa com Minas Gerais.

Uberaba faz parte da rede urbana de Belo Horizonte, mas tem forte ligação com São Paulo, segundo a Região de Influência do IBGE (IBGE, 2007). Daí sua importância na rede urbana mineira e brasileira, considerada pela Regic (IBGE, 2007) uma cidade centro regional, uma cidade média, um polo regional com influência na rede urbana regional por sua oferta de bens e serviços, reforçando sua polarização regional.

Essa centralidade torna Uberaba atrativa para a população do entorno e de outras regiões, como se verifica, por exemplo, no fluxo de migrantes vindos do Nordeste, sobretudo do Maranhão, devido ao crescimento do setor sucroalcooleiro.

A polarização regional é disputada com Uberlândia que, segundo classificação da Regic, é um centro regional B, pois oferece mais bens e serviços, entre eles, sociais, de comunicação, de diversão e de reparos e manutenção. Não obstante a liderança de Uberlândia, Uberaba é importante no contexto regional, com alguma centralidade. Mantém forte relação com a capital e com municípios do interior do estado de São Paulo próximos à divisa MG-SP como Aramina, Igarapava, Ituverava, Miguelópolis e Franca, entre outros, reforçando seu papel na rede urbana regional e nacional.

Em suma, os resultados mostram que o desempenho econômico de Uberaba vincula-se a seu papel em seu contexto regional, ou seja, a suas interações espaciais na escala regional e, ainda que em pequena proporção, também na escala nacional.

\section{Referências}

AMORIM FILHO, O. B. Cidades médias e organização do espaço no Brasil. Geografia e Ensino, Belo Horizonte, v. 2, n. 5, p. 5-35, 1984.

; SERRA, R. V. Evolução e perspectivas do papel das cidades médias no planejamento urbano e regional. In: ANDRADE, T. A.; SERRA, R. V. (Org.). Cidades médias brasileiras. Rio de Janeiro: Ipea, 2001. p. 1-34.

AZZONI, C. R. A lógica da dispersão na indústria no estado de São Paulo. Estudos Econômicos, São Paulo: IPE-USP, n. 16, p. 45-56, 1986.

. Indústria e reversão da polarização no Brasil. Tese (Livre Docência em Economia) - Departamento de Economia e Administração, Universidade de São Paulo, São Paulo, 1985.

BESSA, K. A dinâmica da rede urbana no Triângulo Mineiro: convergências e divergências entre Uberaba e Uberlândia. Uberlândia: Composer, 2007. 
BITTENCOURT, G. M.; LIMA, J. E. Perfil do desenvolvimento rural dos municípios da mesorregião do Triângulo Mineiro e Alto Paranaíba. Disponível em: <http://web.cedeplar.ufmg.br/cedeplar/seminarios/ecn/ecnmineira/2012/arquivos/ Perfil\%20do\%20Desenvolvimento\%20Rural.pdf>. Acesso em: 20 maio 2013.

CANO, W. Concentração e desconcentração econômica regional no Brasil: 1970-95. Economia e Sociedade, Campinas, v. 8, p. 101-41, jun. 1997.

CLEPS JUNIOR, J. Dinâmica e estratégias do setor agroindustrial no cerrado:

o caso do Triângulo Mineiro. Tese (Doutorado em Geografia) - Universidade Estadual Paulista, Rio Claro, 1998.

CORRÊA, R. L. Construindo o conceito da cidade média. In: SPOSITO, M. E. B. Cidades médias: espaços em transição. São Paulo: Expressão Popular, 2007. p. 23-33.

Estudos sobre a rede urbana. Rio de Janeiro: Bertrand Brasil, 2006.

DINIZ, C. C. Impactos territoriais da reestruturação produtiva. In: RIBEIRO, L. C. (Dir.). O futuro das metrópoles: desigualdades e governabilidade. Rio de Janeiro, Revan/ Fase, 2000. p. 21-60.

; CROCCO, M. A. Reestruturação econômica e impacto regional: o novo mapa da indústria brasileira. Nova Economia, v. 6, n. 1, p. 77-103, jul. 1996.

A dinâmica regional recente da economia brasileira e suas perspectivas. Texto para Discussão. Brasilia: Ipea, n. 375, p. 1-46, 1995.

Desenvolvimento poligonal no Brasil: nem desconcentração, nem contínua polarização. Nova Economia, Belo Horizonte, v. 3, n. 1, p. 35-64, set. 1993.

GOMES, M. T. S. O processo de reestruturação produtiva em cidades médias do Oeste Paulista: Araçatuba, Birigui, Marilia, Presidente Prudente e São José do Rio Preto. Tese (Doutorado) - Faculdade de Filosofia, Letras, Ciências Humanas, Universidade de São Paulo, São Paulo, 2007.

GUIMARÃES NETO, L. Desigualdades e políticas regionais no Brasil: caminhos e descaminhos. Planejamento e Políticas Públicas, Brasília: Ipea, n. 15, p. 41-95, jun. 1997.

GUIMARÃES, E. N. Infraestrutura pública e movimento de capitais: a inserção do Triângulo Mineiro na divisão inter-regional do trabalho. Dissertação (Mestrado em Economia) - Centro de Desenvolvimento e Planejamento Regional, Universidade Federal de Minas Gerais, Belo Horizonte, 1990.

A influência paulista na formação econômica e social do Triângulo Mineiro. Disponível em: <http://www.cedeplar.ufmg.br/diamantina2004/textos/ D04A065.PDF>. Acesso em: 10 fev. 2013.

IBGE. INSTITUTO BRASILEIRO DE GEOGRAFIA E ESTATÍSTICA. Estimativa de população 2014. Disponível em: <www.ibge.gov.br>. Acesso em: 10 fev. 2015. 
Produto Interno Bruto dos municípios, 2012. Disponível em: <http://www. ibge.gov.br/home/estatistica/economia/pibmunicipios/2012/default.shtm>. Acesso em: 9 nov. 2014.

. Censo demográfico 2010a. Disponível em: <http://www.ibge.gov.br/home/mapa_ site/mapa_site.php\#populacao>. Acesso em: 17 ago. 2013.

Uberaba. Índice de desenvolvimento humano municipal, 2010b. Disponível em: $<$ http://www.cidades.ibge.gov.br/xtras/temas.php?lang $=E$ codmun=317010 E-idtema $=118$ Esearch=minas-gerais $\mid$ uberaba $\mid \% C 3 \% 8$ Dndice-de-desenvolvimento-humano-municipal-idhm->. Acesso em: 10 abr. 2014.

Região de Influência das Cidades - Regic, 2007. Rio de Janeiro: IBGE, 2008. . Informações sobre os municípios brasileiros, [s.d.]. Disponível em: <http:// cidades.ibge.gov.br/xtras/home.php>. Acesso em: 9 nov. 2014.

LENCIONI, S. A metamorfose de São Paulo: o anúncio de um novo mundo de aglomerações difusas. Revista Paranaense de Desenvolvimento, Curitiba, n. 120, p. 133-148, jan./jun. 2011.

Cisão territorial da indústria e integração regional no estado de São Paulo. In: GONÇALVES, M. L.; BRANDÃO, C. A.; GALVÃO, A. C. F. (Org.). Regiões e cidade, cidades nas regiões: o desafio urbano-regional. São Paulo: Ed. Unesp/Anpur, 2003. p. $465-476$.

. Mudanças na metrópole de São Paulo (Brasil) e transformações industriais. Revista do Departamento de Geografia, n. 12, p. 27-42, 1998.

A reestruturação urbano-industrial: centralização do capital e desconcentração da metrópole de São Paulo - a indústria têxtil. Tese (Doutorado em Geografia) -Faculdade de Filosofia, Letras e Ciências Humanas, Universidade de São Paulo, São Paulo, 1991.

LOURENÇO, L. A. B. O Triângulo Mineiro, do Império à República: o extremo oeste de Minas Gerais na transição para a ordem capitalista (segunda metade do século XIX). Uberlândia, MG: Edufu, 2010.

. A oeste das minas: escravos, índios e homens livres numa fronteira oitocentista, Triângulo Mineiro (1750-1861). Uberlândia, MG: Edufu, 2007.

MINAS GERAIS. Fundação João Pinheiro. Fundação João Pinheiro divulga PIB dos municípios de Minas Gerais, dez. 2013a. Disponível em: <http://www.fjp.mg.gov. br/index.php/noticias-em-destaque/2678-fundacao-joao-pinheiro-divulga-pib-dos-municipios-de-minas-gerais >. Acesso em: 7 dez. 2013.

. Produto interno bruto de Minas Gerais - 1999-2010. Anexo Estatístico, out. 2013b. Disponível em: <http://www.fjp.mg.gov.br/index.php/produtos-e-servicos1/2745-produto-interno-bruto-de-minas-gerais-pib-2>. Acesso em: 8 fev. 2015. 
Desempenho dos municípios mineiros em relação do produto interno bruto (PIB) em 2007. Disponível em: <http://www.fjp.mg.gov.br/>. Acesso em: 10 fev. 2010.

MOTTA, D.; MATA, D. A importância da cidade média. Revista Desafios, ano 6, n. 47, fev. 2009. Disponível em: <http://desafios.ipea.gov.br/>. Acesso em: 10 abr. 2011.

MTE. MINISTÉRIO DO TRABALHO E EMPREGO. Relação Anual de Informações Sociais - Rais. Programa de Disseminação de Estatísticas do Trabalho - PDET. Base de dados referentes a 1985-2013. Disponível em: <http://acesso.mte.gov.br/rais/>. Acesso em: 10 abr. 2015.

NEGRI, B. Concentração e desconcentração industrial em São Paulo (1880-1990). Campinas: Editora Unicamp, 1996. (Coleção momento.)

; PACHECO, C. A. Mudança tecnológica e desenvolvimento regional nos anos 90: a nova dimensão espacial da indústria paulista. Espaço e Debates. São Paulo: Neru, n. 38, p. 62-83, 1994.

A indústria de transformação no estado de São Paulo (1970-89). In. Diagnósticos Setoriais da Economia Paulista: setores de indústria e de serviços. São Paulo: Fundação Seade, 1992. p. 15-79.

As políticas de descentralização industrial e o processo de interiorização em São Paulo: 1970-1985. In: TARTAGLIA, J. C.; OLIVEIRA, O. L. (Org.). Modernização e desenvolvimento no interior de São Paulo. São Paulo: Unesp, 1988. p. 11-37.

PACHECO, C. A. Novos padrões de localização industrial? Tendências recentes dos indicadores da produção e do investimento industrial. Texto para discussão, Brasilia, n. 633, p. 1-38, 1999. Disponível em: <http://www.ipea.gov.br/portal/index.php?option=com_ contentEview=article $E$ id $=3948>$. Acesso em: 27 nov. 2015.

. A fragmentação da nação. Campinas, SP: Unicamp, 1998.

REIS, L. G. L. Centralidade urbana: uma análise do bairro Abadia em Uberaba-MG. Relatório Final de Pesquisa de Iniciação Científica. Uberaba, MG: UFTM, 2012.

SANTOS, M.; SILVEIRA, M. L. O Brasil no início do século XXI. Rio de Janeiro: Record, 2001.

A natureza do espaço: espaço e tempo, razão e emoção. 3. ed. São Paulo: Hucitec, 1999.

Técnica, espaço, tempo. São Paulo: Hucitec, 1994.

SOARES, B. R. Cidades médias: uma revisão bibliográfica. In: ALVES, A. F; FLÁVIO, L. C.; SANTOS, R. A. (Org.). Espaço e território: interpretações e perspectivas do desenvolvimento. Francisco Beltrão: Unioeste, 2005. p. 273-285.

Repensando as cidades médias no contexto da globalização. Revista Formação,

Presidente Prudente, n. 6, p. 55-63, jan./dez. 1999. 
SPOSITO, M. E. B. Novas redes urbanas: cidades médias e pequenas no processo de globalização. Revista de Geografia, São Paulo, v. 35, p. 51-62, 2010.

Nouveaux habitats urbains dans des villes moyennes paulistes - Brésil. Espaces et Sociétés, Nanterre, v. 137, p. 173-188, 2009.

(Org.). Cidades médias: espaços em transição. São Paulo: Expressão Popular, 2007.

. O chão em pedaços: urbanização, economia e cidades no estado de São Paulo. Tese (Livre Docência em Geografia) - Faculdade de Ciências e Tecnologia, Universidade de São Paulo, Presidente Prudente, 2004.

As cidades médias e os contextos econômicos contemporâneos. In:

Urbanização e cidades: perspectivas geográficas. São Paulo: Unesp/FCT, 2001. p. 569-607.

TUNES, R. H. Da desconcentração à reconcentração industrial: análise da relação entre a dinâmica do espaço e a dinâmica dos ramos industriais no município de São Paulo no final do século XX. Dissertação (Mestrado em Geografia) - Faculdade de Filosofia, Letras e Ciências Humanas, Universidade de São Paulo, São Paulo, 2004.

UBERABA. Empreendedores apresentam Andrade Gutierrez como parceira do shopping às margens da BR-050. Uberaba, 2012. Disponível em: <http://www. uberaba.mg.gov.br/portal/conteudo,24481 >. Acesso em: 8 out. 2012.

. PREFEITURA MUNICIPAL DE UBERABA. Uberaba em dados. Uberaba, 2010. Disponível em: <http://www.uberaba.mg.gov.br/portal/conteudo,232,>. Acesso em: 30 mar. 2011. 